\title{
Funções da leitura para estudantes de graduação ${ }^{1}$
}

\author{
Maria Helena Mourão Alves de Oliveira \\ Pontifícia Universidade Católica de Campinas
}

\begin{abstract}
Resumo
Esta pesquisa tem como objetivo identificar as funções da leitura de universitários e assim compreender os seus motivos de leitura. Os sujeitos são 123 estudantes universitários dos cursos de Engenharia e de Fonoaudiologia. O instrumento utilizado foi a Escala de Funções da Leitura. A análise das funções de leitura praticadas pelos estudantes de engenharia e fonoaudiologia evidencia o predomínio das funções Aprendizagem e Utilidade, seguindo-se a função Lazer. A maioria dos estudantes situam-se no nível médio de utilização das funções, sendo que a comparação inter grupos evidencia uma diferença significante em favor do estudante de Fonoaudiologia.
\end{abstract}

Palavras chave: Leitura,Funções,Universitários

\section{Functions of reading used by undergraduate students}

\section{Summary}

This research aims to study the functions of reading identified by undergraduate students and to understand their reasons of reading, by comparing such students according to the use they make of the functions. The sample cinsisted of 123 students, especifically Phonoaudiology and Engineering students.The instrument used for this research was the Functions Reading Scale. The results of this study made evident the predominancy of Learning and Utility functions with a less evident use of Reading for leisure in both of the groups. The majority of the students reveals an average levei of utilization of the functions, mostly evident in the Phonoaudiology group, when the two groups are compared.

Key words: Functions, Reading, Undergraduate students

Desde a sua origem, o homem tem buscado manifestar e fixar seus desejos, necessidades e idéias, utilizando-se de desenhos ou sinais impressos.O crescimento da aplicação social deste processo, que veio a constituir, posteriormente, a leitura e escrita, trouxe junto a valorização do ser humano que, dominando o processo de codificação e decodificação dos sinais gráficos, habilitavase para o ensino deste comportamento. Além disso, a possibilidade de adquirir informação por meio da leitura o qualificava, entre os outros membros de sua comunidade social, para o exercício de várias atividades.

Os vários períodos da história identificam motivos diferentes para a leitura. Assim, a valorização da oratória, para os parlamentares das antigas civilizações greco-romanas, incluía a leitura como um elemento necessário para a formação da cidadania (Gray, 1984).

Na Idade Média, os valores religiosos assim como a necessidade de preparar cidadãos para os serviços da Igreja e para a compreensão das escrituras voltaram a leitura para os motivos religiosos.

Já os séculos XVII e XVIII foram marcados pelas grandes conquistas e definições políticas com a ampliação dos territórios conhecidos. Isto refletiu-se nos motivos de leitura, sendo esta, então, direcionada para a aquisição de conhecimentos e para a obtenção de informações referentes à utilização dos instrumentos criados para a orientação nas viagens ou mesmo para garantir a defesa

\footnotetext{
${ }^{1}$ Este artigo é parte de uma das pesquisas que constituíram a dissertação de mestrado da autora, defendida na PUCCAMP, sob a orientação da $\operatorname{Prof}^{\mathrm{a}} \mathrm{Dr}^{\mathrm{a}}$ Geraldina Porto Witter.
} 
do espaço conquistado.

Somente a partir do século XIX, é que se passou a considerar sistematicamente, os aspectos de lazer e entretenimento que podem ser extraídos dos textos impressos (Gray, 1984), embora esta função de leitura existisse de há muito.

O desenvolvimento econômico e social, observado a partir de 1920, estimulou a ampliação do conhecimento pessoal e social. Nesse período, observou-se, tanto no jovem como no adulto, uma busca mais intensa de informação nas mais diversas fontes, entre as quais se incluíam os livros. Assim a leitura assumiu a função de propiciar o ajustamento pessoal às novas condições de um meio em constante transformação.

A grande implicação social da atividade de leitura fez então a escola e o ensino assumirem uma responsabilidade maior que o próprio processo de alfabetização: ela deve voltar-se para a formação dos hábitos e atitudes de leitura de seus alunos. A missão da escola é instruir, portanto ensinar a ler, e, entretanto, observa-se que os professores encontram muita dificuldade em conseguir que os estudantes se entreguem à leitura (Chartier \& Hebrard, 1995).

A leitura é uma atividade boa, interessante desde que permita às pessoas colocar, conjuntamente, idéias e sentimentos em consonância consigo mesmo e com os outros (Kline, 1994).

Nos primeiros estágios do aprendizado desta atividade cognitiva, o estudante despende esforços no setido de habilitar-se na decodificação dos símbolos; posteriormente, nos estágios escolares superiores, ele é encaminhado para reconstruir, compreender, assimilar e usar a informação extraída de diferentes suportes para atender a muitos objetivos ou funções. Entretanto, depois de completar a escolaridade, muitos ou talvez a maioria, não façam da leitura um hábito, um prazer ou um instrumento de informação (Cramer \& Castle, 1994).

A importância da formação dos hábitos de leitura, já era enfatizada nos meados do século XIX, quando no terreno do embate político aparece clara a posição republicana à favor da formação de sujeitos habilitados à busca do conhecimento e portanto, à constituição de sujeitos emancipados (Chartier \& Herbrard, 1995).

Estes fatos demonstram que a leitura, além de representar um papel relevante na formação do indivíduo por se constituir em uma forma exemplar de aprendizagem (Bamberg, 1975), reflete também os anseios, as necessidades, os ideais e aspirações da sociedade.

Com isto, a leitura e o livro assumem uma nova importância. Eles também atendem aos motivos e interesses do leitor, graças à possibilidade de seleção individual do texto impresso.

Cada ser humano pode encontrar nos livros uma ajuda para seu próprio desenvolvimento, para constituir o seu senso-crítico e para atuar seletivamente com diversos meios de informação. Os motivos de leitura para o homem contemporâneo, além, do aprendizado e crescimento social, identificam outros aspectos. Gray (1984) listou alguns desses motivos que refletiam a preocupação com o manter-se informado sobre os fatos para assim definir objetivos profissionais precisos, garantir o sucesso pessoal, desenvolver o próprio conhecimento e experimentar situações de prazer.

Quando nos referimos aos motivos, designamos as tendências e intenções determinadas logicamente. De outro lado, os interesses estão relacionados com as atitudes e experiências afetivas. Os dois juntos, motivos e interesses, refletem o momento de vida de um sujeito.

A primeira motivação para a leitura tem por base o prazer de pôr em prática uma habilidade adquirida, cujo aprimoramento transforma a leitura em fonte de exercício da imaginação, da vontade e do discernimento (Bamberg, 1975). 
Em uma outra etapa do processo de aprendizagem da leitura, a curiosidade intelectual e a necessidade de ampliação do próprio conhecimento e de enriquecimento das próprias idéias direcionam a leitura para interesses de aprendizagem, para a formação de uma filosofia de vida e para uma melhor compreensão do mundo.

Atendendo a motivos internos e muitas vezes inconscientes, a leitura é utilizada para reviver momentos da própria vida do sujeito, para encontrar-se com coisas e personagens novos e assim construir uma realidade diferente em um universo imaginário.

Outros interesses preenchidos, mais tarde, por meio da leitura referem-se ao desejo de auto afirmar-se, a busca de um ideal, de uma orientação ou um modelo de vida. A leitura se constitue, também, em uma atividade de prazer.

Ojiehrl (1952), citado em Bamberg (1975), distinguiu, em função dos motivos citados acima, quatro tipos de leitura. A leitura de informação, considerada a mais utilizada, principalmente pelo leitor adulto, volta-se tanto para a obtenção de orientação na vida e no mundo, quanto para a satisfação de necessidades pessoais e sociais. A leitura de fuga liga-se à necessidade de fugir da realidade. Através desta leitura busca-se o sucesso, o prestígio e o prazer não encontrados na vida cotidiana. Própria do leitor infanto-juvenil, esta função de leitura também é encontrada entre os motivos de leitura do adulto, mas com menor freqüência. A leitura literária tem uma função estética, aprimorando a linguagem do leitor, permitindo-lhe constituir um modelo literário próprio. Finalmente, a leitura cognitiva, voltada para a compreensão de si mesmo, dos outros e do mundo, exige do leitor receptividade e senso crítico, o que a caracteriza como própria do leitor adulto.

Na atividade de leitura visando atender a esses objetivos, são ativados fatores psicológicos que irão influenciar e direcionar a decisão do leitor que, certamente, possui outras opções além da leitura. Tais fatores que envolvem auto-conceito, expectativas de sucesso, de prazer ou utilidade, além da pressão social e cultural, formam-se simultaneamente ao desenvolvimento da habilidade de ler, e formatam a atitude de leitura do sujeito (Cramer \& Castle,1994).

Com o objetivo de identificar as funções da leitura e assim compreender porque os homens lêem, foram realizados alguns estudos (Greaney, 1990; Wolfson, Manning e Manning, 1984). Muitos deste focalizaram determinantes pessoais nos interesses de leitura, como idade, sexo fatores sócio-econômicos entre outros (Greaney, 1990).

Deahrendorf, (1967) foi citado por Bamberg (1975) por um estudo realizado em Hamburg, considerando os motivos, interesses e funções de leitura manisfestados por crianças e adolescentes. A partir dessa pesquisa, o autor formulou as seguintes conclusões:

- a leitura atende a um sentimento de poder, de auto-realização;

- as crianças procuram, por meio da leitura, um escape à monotonia do cotidiano;

- no diálogo com o autor, mediado pelos textos, as crianças buscam remediar a solidão;

- os leitores infantis gostam de viver o papel do personagem, de se integrar e participar dos eventos do livro, exercitando a imaginação;

- na adolescência, quando o leitor já identifica os traços psicológicos dos personagens, efetiva-se a função de auto-conhecimento da leitura; e

- é também nesta fase que se distingue a leitura de aprendizagem, considerando-se que por volta dos 14 anos o sujeito já se direciona para a formação de hábitos permanentes de leitura.

Em um estudo realizado no Brasil, tendo como sujeitos alunos do magistério e do curso prévestibular, Ferraza (1986) agrupou as funções da leitura como atendendo a 5 aspectos: 
(l)como elemento de enriquecimento, formação intelectual e conhecimento;

(2)como fator de desenvolvimento da criatividade e da capacidade analítico-sintética;

(3)como fator de desenvolvimento da fala, do vocabulário, da expressão escrita e do domínio da gramática;

(4)como elemento de integração do sujeito ao meio e um instrumento de atualização cultural; e

(5)como elemento de lazer e entretenimento.

Greaney (1990), realizando um estudo transcultural, formulou uma conceptualização mais abrangente das funções mais essenciais da leitura.

$\mathrm{O}$ autor da pesquisa afirmou que as funções são determinadas pelas necessidades pessoais, as quais dependem de fatores psicológicos (ex: inteligência, personalidade e experiência) e fatores sociais (ex: posição sócio-econômica, contexto e ambiente, nível e tipo de experiências).

A leitura fornece os reforçadores que atendem tanto às necessidades pessoais estabelecidas ao longo da história de vida do sujeito, como também às sociais, que lhe dão motivos atuais específicos para ler em busca de informação ou como atividade que será valorizada socialmente.

Assim, Greaney (1990) reforçou a validade de utilização da perspectiva transcultural, uma vez que os valores culturais próprios de cada região são focalizados como reforçadores presentes no meio.

A partir deste estudo o autor identificou dez funções:

(1)aprendizagem - voltada para a ampliação e desenvolvimento do conhecimento; ex: leio porque me ajuda a aprender algo novo;

(2)lazer - quando a leitura é feita por ser divertida e interessante; ex: leio porque é interessante e me faz feliz;

(3)fuga - é a leitura feita para esquecer aborrecimentos; ex: leio porque sinto solidão.

(4)estímulo - quando a leitura favorece a imaginação, a fantasia; ex: leio para pôr pensamentos na minha cabeça;

(5)preencher o tempo - é a leitura feita por falta de outra atividade; ex: leio para matar o tempo;

(6)alvos sociais definidos - quando a leitura se volta para a satisfação das necessidades pessoais e sociais; ex: leio porque me ajudará a ter um bom trabalho;

(7)moralidade - é a leitura que atende à formação moral e ética; ex: leio para saber mais sobre a minha religião;

(8)auto-respeito - quando a leitura se volta para a auto-realização; ex: leio para me tomar uma pessoa importante;

(9)flexibilidade - quando a leitura é priorizada entre outras formas de lazer; ex: leio quando não há nada excitante na T.V. e

(10)utilidade - a leitura utilizada para o aprimoramento da linguagem oral e escrita; ex: leio porque me ajuda com os trabalhos que irei realizar.

Com base nos fatos teóricos expressos, pode-se considerar algumas hipóteses sobre as variáveis que orientam (ou não orientam) o comportamento de leitura dos estudantes em geral e do universitário em particular.

É válido supor que este já tenha definido seus alvos pessoais, profissionais e da carreira. Neste contexto, pode-se incluir o comportamento de leitura, no qual a energia motivacional direciona-se ao atendimento das necessidades específicas.

Todo comportamento do ser humano é constituído de atos ou alvos intermediários, que se 
organizam em função de um objetivo ou alvo final.

Este objetivo define uma das características diferenciais do comportamento humano, no que se refere à possibilidade de sustentá-lo, mantendo-o por um longo período de tempo (Gager, 1988).

A manutenção deste comportamento sofre, também, a interferência de reforçadores, ou seja, tudo o que o indivíduo ou o meio valorizem positivamente. A identificação de um estímulo ou situação, como um reforçador positivo ou não, envolve as necessidades, valores, atitudes e interesses, entre outros.

Assim, podemos supor que o conhecimento das funções de leitura identificadas pelos estudantes, define a sua necessidade intelectual, sua necessidade estética e de auto-atualização e, portanto, o seu nível de maturidade como leitor.

Reconhecendo a importância da leitura na formação pessoal e profissional do estudante universitário, este estudo teve como objetivos: relacionar as funções de leitura identificadas pelos estudantes de Engenharia; relacionar as funções de leitura identificadas pelos estudantes de Fonoaudiologia; comparar os dois grupos com referência às funções.

\section{Método}

\section{Sujeitos}

Serviram de sujeitos da pesquisa 123 estudantes universitários, sendo 62 alunos do curso de Engenharia e 61 alunos do curso de Fonoaudiologia. Todos os sujeitos estavam cursando a quarta série dos respectivos cursos.

Os sujeitos do sexo feminino correspondiam a 67\% da amostra, sendo que no Curso de Fonoaudiologia este percentual foi de 98\% e no de Engenharia, 35\%.

A idade dos sujeitos variou de 20 a $3 \mathrm{~m}$ a 40 anos e $4 \mathrm{~m}$, com $73 \%$ dos sujeitos situando-se na faixa de 20 a 25 anos.

O trabalho remunerado era realizado por 68\% dos alunos de Engenharia e 33\% dos sujeitos de Fonoaudiologia.

\section{Material}

$\mathrm{O}$ instrumento de pesquisa utilizado foi a Escala de Funções da Leitura proposta por Greaney e Newman (1990) traduzida, adaptada e ampliada por Witter (1990), e pré testada anteriormente.

Como dados de identificação dos sujeitos, solicitou-se: o nome, a idade, a profissão, o sexo e a escolaridade.

A Escala é constituída de cinqüenta ítens que tiveram por base as dez funções da leitura relacionadas no artigo de Newman e Greaney (1990). Para cada questão, o sujeito deveria responder de acordo com uma escala de avaliação correspondente a: muito, mais ou menos, pouco ou nada.

\section{Procedimento}

A coleta dos dados foi realizada pela própria pesquisadora, tendo-se utilizado de uma única sessão para cada grupo (GF e GE). Não existiu delimitação de tempo para a resposta, sendo o instrumento aplicado coletivamente em sala de aula. O tempo médio gasto para a realização desta atividade foi de aproximadamente 20 minutos. 


\section{Resultados}

As Funções da Leitura, segundo a Escala de Greaney e Newman (1990), identificadas pelos sujeitos do Curso de Engenharia (GE) e de Fonoaudiologia (GF) estão descritas conforme a porcentagem de ocorrência.

Os ítens que apresentaram porcentagem acima de $50 \%$ para os dois grupos na referência "muito", são o 3 e o 9 relativos à função Aprendizagem, e os ítens 5 (Lazer) e 18 (Alvos Sociais Definidos).

Entre 50 e 20\% na opção "muito", ainda para os dois grupos, situam-se os ítens 7, 35 e 41 todos relativos à função Utilidade; 26 e 31 que dizem respeito à Moralidade; 28 e 42 concernentes à Flexibilidade; 10 enfocando Lazer e 40 referente à leitura como Estímulo.

Os itens 1 e 25 (Lazer),2 e 12 (Estímulo), 34 e 50 (Auto-Respeito), 3 (Aprendizagem), 37 (Fuga) e 43 (Preencher o Tempo) situam-se entre os percentuais de 10 a 20\% na referência "muito".

Abaixo de 10\%, na opção "muito" ficam os ítens das funções: Preencher o tempo (11-39-4448); Alvos Sociais Definidos (38-46 e 49); Auto-Respeito (15 e 32); Fuga (16 e 23); Flexibilidade (27) e Moralidade (33).

O percentual acima de $80 \%$ na referência "muito" só é identificado no grupo de alunos de Fonoaudiologia, em relação às funções Aprendizagem (3) e Alvos Sociais Definidos (18).

Entre os percentuais 50 e $80 \%$, além daqueles já citados, no grupo de alunos de Fonoaudiologia situam-se o item 14 da função Alvos Sociais Definidos, o 47 (Utilidade) e o 42 relativo a Aprendizagem.

Na Fig. 01 estão representadas as médias das funções de leitura segundo os dados obtidos nos dois grupos GF e GE.

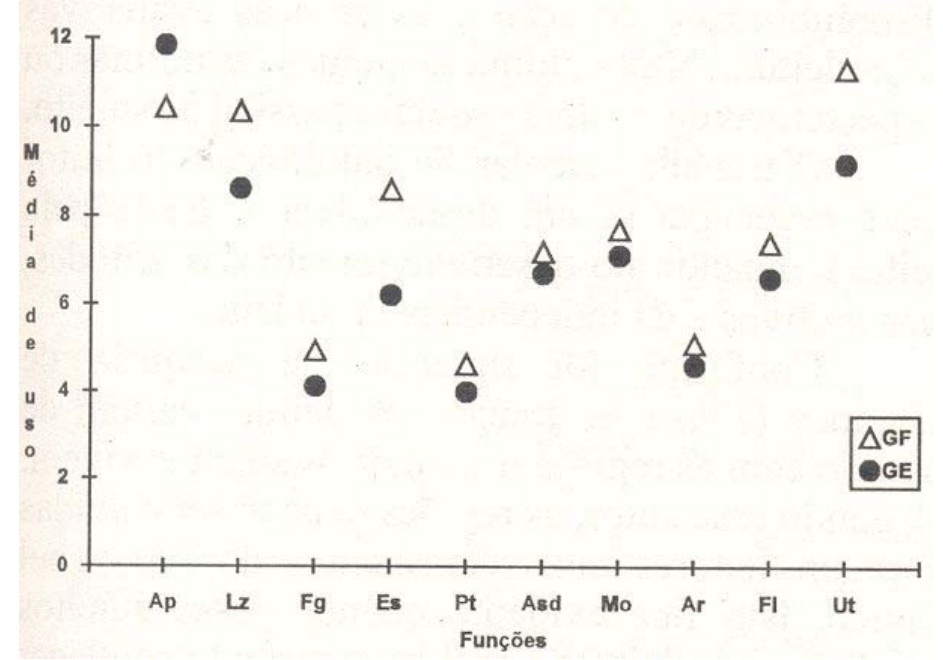

Figura 1. Funções da Leitura nos grupos de Fonoaudiologia e Engenharia.

As funções Aprendizagem (GE = 11,83 e GF = 10,42) e Utilidade ( $\mathrm{GE}=9,19$ e GF $=11,34$ ) são predominantes nos dois grupos de sujeitos.

As funções Fuga $(\mathrm{GE}=4,11$ e GF = 4,93) e Preencher o Tempo $(\mathrm{GE}=3,98$ e GF = 4,62) aparecem com os menores índices.

Nos dois grupos o índice ou ocorrência da função Lazer é apreciável, com valores de GE = 
8,62 e GF = 10,34. Também com alto índice de ocorrência, a função Estímulo aparece para o grupo de estudantes de Fonoaudiologia.

Para os dois grupos, com uma variação média de 6,5 a 7,5 pontos, situam-se as funções Alvos Sociais Definidos, Moralidade e Flexibilidade.

Os dados gerais mostram similaridade de desempenho entre os dois grupos de sujeitos.

A Tabela 01 sintetiza os três níveis de média de uso das funções da leitura, considerando o nível alto com valores de 11 a 15, o médio de 6 a 10 e o baixo de 0 a 5 .

Tabela 1. Desempenho das Funções de Leitura para os Grupos G.E. e G.F.

\begin{tabular}{|c|c|c|c|c|}
\hline Resultado & Nível & G.E. & G.F. & Total \\
\hline $11-15$ & alto & 2 & 4 & 6 \\
\hline $6-10$ & médio & 46 & 55 & 101 \\
\hline $0-5$ & baixo & 14 & 2 & 16 \\
\hline Total & & 62 & 61 & 123 \\
\hline
\end{tabular}

O desempenho das funções foi dividido, em termos qualitativos, em três níveis, tendo por base a distribuição teórica prevista no instrumento (de zero a 15).

A maioria dos sujeitos (101) situa-se no nível médio de utilização das funções da leitura.

Para a análise estatística da distribuição da utilização das funções, nos dois grupos (GF e GE), foi utilizado o teste $X^{2}$ (Siegel, 1956).

Os níveis, originalmente em número de três, foram reduzidos a dois pela inclusão do nível alto no nível médio. Isto foi realizado em decorrência da baixa freqüência de sujeitos no primeiro grupo.

A hipótese básica (Ho) considerou que a utilização das funções de leitura independe do curso ao qual o aluno estava vinculado $\left(\mathrm{X}^{2}=\mathrm{O}\right)$. Como hipótese alternativa $(\mathrm{H} 1)$, considerou-se que a utilização das funções de leitura depende do curso freqüentado pelo sujeito $\left(X^{2} \neq 0\right)$. $O$ nível de significância foi de 0,05 , o n.g.1. $=1$ e $\mathrm{X}_{\mathrm{c}}^{2}=3,84$.

O resultado final identifica o valor de X2 igual a 10,12, portanto, a diferença entre os grupos é significante em favor do GF, o qual usa mais intensamente o nível médio do que o faz o GE, onde um percentual apreciável de sujeitos $(14=22,58 \%)$ atua em nível baixo de uso das funções.

Para a análise estatística da distribuição dos sujeitos nos três níveis de desempenho das funções de leitura, foi aplicado o teste $X^{2}$ (Siegel, 1956).

Como hipótese nula, foi estabelecido que não ocorreu diferença significante entre os três níveis $\left(\mathrm{Ho}=\mathrm{X}^{2}\right)$. Como hipótese alternativa, considerou-se a ocorrência de diferença entre os três níveis $\left(\mathrm{H}_{1}>\mathrm{X}^{2}\right)$. O nível de significância foi de 0,05 , o n.g.l. $=2$ e o $\mathrm{X}_{\mathrm{c}}{ }^{2}=7,82$.

O resultado final identifica o valor de $X^{2}$ igual a 132,92, portanto, a diferença de distribuição no uso das funções é significante em favor do uso médio de funções da leitura.

\section{Discussão}

Costuma-se atribuir à leitura funções relacionadas à realização pessoal na qual se incluem aspectos cognitivos, afetivos, estéticos e criativos.

Além da dimensão individual, as funções da leitura têm relação com os aspectos sociais que, 
orientam e reforçam todo comportamento humano no atendimento de suas necessidades, perspectivas e realizações.

Nesta relação pessoal-social, o hábito de leitura forma pessoas abertas ao intercâmbio de idéias, orientadas para o futuro, habilitadas ao planejamento, desenvolvimento e formulação de princípios técnico-científicos, forma, como foi descrito por Freire (1990), sujeitos atentos à leitura do mundo e de seus significados, o que os toma participantes e responsáveis pelo desenvolvimento sócio-cultural.

Ao assumir esta posição o sujeito-leitor atualiza alguns motivos psicológicos, entre os quais o auto respeito, a auto realização, a segurança e o sucesso, entre outros.

Essas necessidades direcionam o interesse para uma leitura específica que, na medida em que atende ou satisfaz o motivo desencadeador, se transforma em uma nova energia motivacional.

Como foi comentado na introdução deste capítulo, a criança tem como primeiro motivo para a leitura a auto satisfação de poder ler; segue-se o período no qual a curiosidade mantém .a necessidade de ler. A maturidade como leitor é atingida quando a leitura se transforma em uma força motivacional em si mesma, constituíndo-se em um comportamento permanente (Smith, Dechant, 1961).

A leitura passa a se constituir, então, em um meio de aprendizagem, de lazer e de estímulo ao pensamento. O leitor maturo busca a leitura para descobrir novos interesses e para afastar-se das preocupações diárias.

A análise das funções de leitura praticadas pelos estudantes de Engenharia e Fonoaudiologia, evidenciou o predomínio das funções Aprendizagem e Utilidade, o que possivelmente esteja de acordo com a fase de vida em que estão.

Uma observação mais detalhada das afirmativas, relacionadas à função Utilidade, a direcionam para o aspecto da aprendizagem fundamentalmente acadêmica.

Quando esses estudantes foram questionados com referência às opções de leitura, observouse o predomínio da leitura do livro de estudo. Esta resposta confirma a força da função aprendizagem para os sujeitos aqui focalizados.

Lopes \& Ribeiro (1992), analisaram as funções da leitura para pós-graduandos em Biblioteconomia e, também identificaram a aprendizagem como aquela mais presente nos objetivos de leitura desses estudantes. É importante destacar o fato do amadurecimento acadêmico não ter refletido alguma modificação nos propósitos de leitura dos sujeitos.

Este fato parece concretizar-se no estudo de Buriti e col (1995), no qual não foram identificadas diferenças significantes no uso das funções pelos estudantes de graduação e o de pós graduação.

O direcionamento para um leitura seletiva, tem em sua base fatores psicológicos que formatam a atitude do sujeito/leitor. Alexander \& Filler (1976, apud McKenna, 1994) definem atitude como um sistema de sentimentos relacionados à leitura e que podem determinar comportamentos de aproximação ou afastamento em relação ao livro.

Mathewsons(1994), amplia esta definição de atitude, incluindo, além dos aspectos afetivos, a disponibilidade de ação e as crenças avaliativas sobre leitura. Nesta última se incluem as normas ou expectativas do contexto social e pessoal do sujeito.

O trabalho escolar de habilitação do leitor deve preocupar-se em desenvolver o gosto pela leitura, atuando no desenvolvimento das atitudes, dos motivos e da independência do leitor. 
Conforme foi sugerido na pesquisa de Greaney (1990), as funções de leitura variam de acordo com as regiões nas quais os sujeitos vivem. Segundo esse autor, as regiões mais desenvolvidas formam leitores mais conscientes do seu papel cívico. Isto fica evidente quando esses sujeitos relatam que a leitura é realizada visando conhecer para ajudar o seu país. Para viver a democracia a leitura é essencial. Todo cidadão faz parte do governo e deve conhecer o povo que atua e os fatos que ocorrem para poder formular julgamentos objetivos e críticos (Stauffer, 1969). No entanto, mesmo nas atuais circunstâncias sócio-políticas vivenciadas pelos brasileiros, os universitários, pouca atenção, deram à leitura executada para atender a esta função.

Realmente, no presente estudo, os aspectos relativos à função Utilidade referente ao país ou governo, tiveram baixo índice de referência, sugerindo que a leitura não é considerada como um instrumento para a formação da cidadania. Isto pode estar refletindo a ineficiência do sistema educacional para a formação do cidadão.

A função Flexibilidade, com baixo nível de utilização, reflete um leitor dependente que, conforme eles mesmo se identificam, realizam a leitura por indicação dos outros, particularmente, do professor.

A leitura mais independente, que pode estar relacionada com a função Lazer, tem como suporte os jornais e as crônicas de jornais, leitura referida pelos sujeitos dos dois grupos, como diária.

Os fatos orientam o questionamento em relação ao papel da escola, do $1^{\circ}$ ao $3^{\circ}$ grau, que, não estimulando a independência do sujeito como leitor interfere na manutenção do interesse pela leitura, reduzindo-o à satisfação de umas poucas necessidades como foi aqui constatado.

Além de se repensar o processo de ensino-aprendizagem, deve-se focalizar a formação do próprio professor como leitor, tendo-se como referência sua flexibilidade e maturidade. Pode-se também questionar seu conhecimento sobre os motivos e interesses de seus alunos na escolha do material de leitura.

A leitura utilizada para atender à função Estímulo, e que teve um nível de identificação mais alto no grupo de estudantes de Fonoaudiologia $(\mathrm{Mu}=8)$ do que para os estudantes de Engenharia $(\mathrm{Mu}=6)$ nos permite formular duas hipóteses.

A primeira apóia-se na característica formativa dos dois cursos, considerando-se que um pertence à área de exatas e o outro à área de humanas. Como foi caracterizado no início deste trabalho os sujeitos provenientes do curso de Engenharia eram, em sua grande maioria do sexo masculino, portanto, o inverso da situação dos estudantes de Fonoaudiologia.

Norvell (1958 apud Smith e Dechant, 1961) estudando o interesse de leitura de escolares do sexo masculino e feminino, verificou que esta variável é uma das mais determinantes durante o período de escolaridade universitária. Relata, também, que, nos ciclos escolares inferiores, o material de leitura utilizado atende de forma particular os motivos e interesse das meninas, desenvolvendo mais intensamente a fantasia, a imaginação, o que contraria o motivo e interesse dos meninos desta mesma faixa etária, mais ligados à aventura e ao esporte.

Uma outra hipótese considera que a partir dos 12 anos, os meninos se voltam para as atividades esportivas, afastando-se dos livros.

Como é citado por Leng (1968 apud Carter, 1978) muitos meninos se afastam da leitura, negando seu interesse e desejo de ler, porque os valores culturais atribuem esta atividade como própria do sexo feminino.Este mesmo aspecto é citado por Mathewson (1994) quando enfatiza o 
papel das normas subjetivas,ou das crenças e expectativas dos componentes do grupo social. São estes, fatores interferentes nas atitudes do sujeito leitor.

Este fato se confirma no relato de professores universitários pesquisados sobre suas lembranças da aquisição e desenvolvimento de leitura (Carvalho, 1992). Segundo dados dessa pesquisa na faixa de escolaridade de $2^{\circ}$ grau, muitos sujeitos diminuíam a atividade da leitura em decorrência da pressão social.

As funções "Preencher o Tempo" e "Fuga" que apresentaram baixo índice de identificação, podem ter sido rejeitadas pela sua "tonalidade negativa" (Greaney, 1990). Entretanto entre as diversas afirmações possíveis relativas a essas funções, uma se refere à possibilidade de afastar-se da agitação da vida moderna, assumindo uma postura reflexiva e avaliativa sobre si mesmo e sobre o texto.

Herth \& Szostak (1995) apoiados na Teoria da Experiêcia "tima (Csikszentmihalyi, 1991) pesquisaram a importância da leitura para sujeitos idosos impossibilitados de atividade física independente. Os autores relatam que ler assume a função de afastar os sujeitos de seus problemas, mantendo-os em contato com o mundo, conseqüentemente, afastando o sentimento de solidão.

Para o presente estudo, a distribuição das funções demonstrou que os sujeitos dos dois grupos incluem-se no nível médio de utilização, caracterizando um escore inferior ao esperado em universitários.

O interesse, que determina o porquê a leitura é realizada, apresenta uma substancial e marcada relação com a leitura compreensiva (Smith, 1961).

Assim como o objetivo da leitura organiza o raciocínio para a apreensão do texto, o interesse pelo conteúdo transmitido abre o espírito e a imaginação para a reformulação ou ampliação do conhecimento prévio pela incorporação de novas informações.

O estado afetivo do sujeito define os objetivos e expectativas com relação ao conteúdo, à organização do tempo e ao produto final. Assim, um texto altamente interessante ou avaliado como importante para o objetivo do sujeito, será alvo do máximo de processamento e de persistência (Ruddel \& Speaker(1995).

Como é citado por Bamberg (1975), é grande a responsabilidade da escola na formação de leitores motivados. Esta responsabilidade se inicia na identificação de métodos eficientes de ensino, propícios a estimular, simultaneamente, tanto o aluno menos dotado como o habilitado.

Para isto, o professor deverá conhecer as preferências de leitura em cada faixa etária e nível sócio-econômico; deverá, também, procurar identificar as diferenças individuais decorrentes de um estilo de vida próprio de um ambiente familiar único.

A integração da biblioteca (e do bibliotecário) às atividades de ensino permitem um acompanhamento das diversas escolhas de leitura realizadas pelos alunos. Esta proximidade com os temas escolhidos possibilita ao professor desenvolver um processo de discussão sobre os pontos importantes do texto, acompanhando a interpretação oferecida, avaliando o nível de compreensão e a extensão da integração do leitor com o autor e com o texto.

A constituição do hábito de leitura no estudante inicia-se pelo uso do livro para o atendimento de interesses internos, pessoais; segue-se pela conscientização de sua importância no desenvolvimento do papel profissional e social do sujeito atingindo, então, uma posição sólida entre as hierarquias de hábitos.

Os dados aqui apresentados indicam a necessidade de programas de apoio à leitura para o 
universitário visando garantir-lhe maior flexibilidade e capacidade para atender a todas as funções da leitura.

\section{Referências}

Bamberg, R (1975). Éstude et documents d'infonnation: développer l'habitude de Ia lecture. UNESCO, 72: 355.

Buriti, B.A.; Gargantini, M.B.M.; Mendonça, G.G.L.; Oliveira,M.H.M.A.(1995) As funções da leitura para graduandos e pós-graduandos (no prelo).

Carter, S.M. (1978). Interests and reading Journal of Research and Development in Education. 11 (3): 6168.

Carvalho, A.M.; Dantas, L.; Franchito, A.; Mendonça, C.F.; Oliveira, M.H.; Trento, E. e Witter, C.(1992). Memória de leitura em professores universitários, (mimeo).

Chartier,A.M.; Hébrard,J.(1995) Discursos sobre a leitura-1880-1980.trad. O. Biato e S. Bath.S.P: Ática.

Cramer,E.H. \& Castle,M. (1994) Develloping lifelong readers in E.Cramer \& M.Castle. Fostering the love of reading:the . affective domain. Newark: IRA.

Ferraza, J.L. (1986) Leitura e consciência: princípios para uma leitura escolar pedagógica. S.P. Dissertação de Mestrado. EDUSP.

Freire, P.; Macedo, D. ( 1990) Alfabetização: leitura do mundo leitura da palavra. Rio de Janeiro :paz e Terra.

Gager e Berliner. (1988).Educational Psychology. New Jersey:

Gray, W. S.(1984). Reading. Newark: IRA.

Greaney, V. (1980). Factors related to amountand type of leisure time reading. Reading Research Quaterly, 15: 337-357.

Greaney, V.; Newman, S.B. (1990) The function of reading: a cross cultural perspective. Reading Research Quaterly, 25 (3): 172-195.

Herth,K.A.; Szostak-Rane, D. (1995). Pleasure reading, other activities, and loneliness in later life. Journal of Adolescent \& Adult Literacy, 39(2):100-109.

Kine,L.W. (1994) Reading and society: lessons from the world out there. in E.H.Cramer \&. M. Castle. (ed).Fostering the love ofreading.Newark:IRA.

Lopes, T. M. J.; Ribeiro, M. S. P. (1992) Funções da leitura entre pós-graduandos em biblioteconomia. Transinformação, 4 (1,2,3): 45-54.

Mckenna,M.C. (1994) Toward a model of reading attitude acquisition in E.H.Cramer e M. Castle. (ed). Fostering the love ofreading.Newark: IRA.

Mathewson, G. C. (1994). Model of attititude influence upon reading and learning to read.in M.R.Ruddell.;R.B.Ruddel \& H. Singer (ed). Theoretical models and processes of reading. Newark:IRA

Ruddel, R. B. \& Speaker, R. (1985). The interactive reading process:a model. in H.Singer .\& R.B.Ruddel. (eds) Theoretical models and processes of reading Newark: IRA.

Siegel, C.W. (1956).Non parametric statistics for the behavioral sciences. New York: Mac Graw Hill.

Smith, H. e Dechant, G.(1961). Psychology in teaching reading. Englewood Cliffs: Prentice-Hall.

Stauffer, R.G. (1969) Directing reading maturity as a cognitive process. NY: Harper \& Row.

Wolfson, B.1.; Manning, G.; Manning, M.(1984). Revising what children say their reading interests are. Reading World, 24, 4-10. 